\title{
RESTORATION AUTHENTICITY OR REALITY - A CASE STUDY
}

\section{DAVID T. BIGGS}

\author{
Biggs Consulting Engineering \\ 26F Congress St. \#305 \\ Saratoga Springs, New York, USA \\ e-mail: biggsconsulting@att.net
}

Keywords: Restoration, Heritage, Masonry, Venice Charter, Authenticity

\begin{abstract}
In recent decades, the Venice Charter of 1964 [1] has provided the guiding principles for the conservation and restoration of ancient monuments. However, many interpret these principles as applying to historic structures in general, and not just monuments.

The articles in the Restoration section of the Charter have several interesting statements (underlines are for emphasis) that are open to interpretation. In many cases, these statements cause a conflict of priorities, especially with funding being the overriding issue. In addition, local and national heritage agencies sometimes take a more liberal approach to restoration, particularly regarding authenticity.
\end{abstract}

The statements under discussion are:

"ARTICLE 9. The process of restoration is a highly specialized operation. Its aim is to preserve and reveal the aesthetic and historic value of the monument and is based on respect for original material and authentic documents. It must stop at the point where conjecture begins, and in this case moreover any extra work which is indispensable must be distinct from the architectural composition and must bear a contemporary stamp."

"ARTICLE 10. Where traditional techniques prove inadequate, the consolidation of a monument can be achieved by the use of any modem technique for conservation and construction, the efficacy of which has been shown by scientific data and proved by experience."

"ARTICLE 12. Replacements of missing parts must integrate harmoniously with the whole, but at the same time must be distinguishable from the original so that restoration does not falsify the artistic or historic evidence."

Each of these statements affects the authenticity of the restoration. But, maintaining authenticity of the restoration has to be balanced with the reality of maintaining our heritage buildings on limited resources. Can it be done?

This paper discusses these challenges in the context of the 1996 restoration of a threestory, 19th century brownstone. The paper will include the conflicts with recommendations for an authentic restoration in accordance with the Charter principles. The work was performed on a limited budget and attempted to address the Owner's desire for an aesthetic solution. Finally, an assessment of the restoration after 23 years will be included. 


\section{INTRODUCTION}

The question of authenticity in preservation has been debated for decades. Prior to 1964 there was no general consensus of what degree of authenticity was appropriate. What first was conservation of cultural heritage has expanded to be considered historic preservation. The forms include such objects as archaeological sites, artistic sculptures and paintings, cultural landscapes, buildings, and monuments.

Boito in 1883 presented a series of preferences for dealing with cultural properties to an Italian technical congress of architects and engineers [2]. The preferences adopted included a top priority to consolidation over repair. Next in priority would be repair rather than restoration. Proposed interventions were to be both identifiable and labelled as modern. Any elements or features that were to be removed should be documented and preserved for display at the site. He acknowledged that there may have already been renovations or additions subsequent to the original construction that now was a part of the history of site. Those renovation and additions might be deemed inferior or effectively hiding the original construction.

\subsection{Athens Charter}

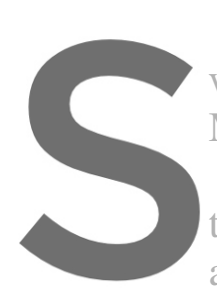

Followers of Boito which adopted many MONUMENTS states:

"The experts heard of Boito instrumental in c
ito's ideas. Speci
onuments. They a creating the
ecifically, Section
ons concerning
approved the
especially of rei first Athens Charter in
netion IV. RESTORA
reinforced eoncrete. in 1931
ATION
material
he resqu

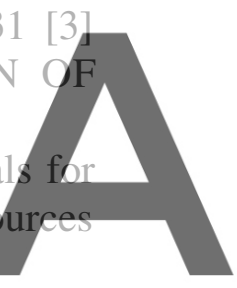
at the disposal of modern technique and more especially of reinforced eoncrete.
They specified that this work of consolidation should whenever possible be concealed in

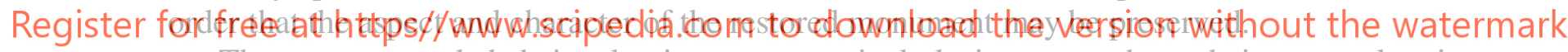

They recommended their adoption more particularly in cases where their use makes it possible to avoid the dangers of dismantling and reinstating the portions to be preserved."

No specific techniques or methods were proposed but highlighted their concern over the potential damaging use of reinforced concrete. They did recommend "That, in each country, the architects and curators of monuments should collaborate with specialists in the physical, chemical, and natural sciences with a view to determining the methods to be adopted in specific cases;". Scientific determination was essential to deciding a course of action. Interestingly, authenticity is not discussed.

\subsection{Venice Charter}

Possibly reacting to the reconstruction of buildings and monuments following two world wars, the 1964 Venice Charter [1] professed to save our heritage through preservation authenticity. It provided a tool for fervent preservationists to limit uncontrolled development.

Generally, only preservationists study such documents. Since they are not legally binding, local implementation is highly dependent on local advocates.

The Restoration articles set new standards for preservation and authenticity. 
“ARTICLE 9. The process of restoration is a highly specialized operation. Its aim is to preserve and reveal the aesthetic and historic value of the monument and is based on respect for original material and authentic documents. It must stop at the point where conjecture begins, and in this case moreover any extra work which is indispensable must be distinct from the architectural composition and must bear a contemporary stamp."

"ARTICLE 10. Where traditional techniques prove inadequate, the consolidation of a monument can be achieved by the use of any modem technique for conservation and construction, the efficacy of which has been shown by scientific data and proved by experience."

"ARTICLE 12. Replacements of missing parts must integrate harmoniously with the whole, but at the same time must be distinguishable from the original so that restoration does not falsify the artistic or historic evidence."

Subsequently numerous efforts have been made to refine the intent of authenticity including the 1965 UNESCO Archaeological Guidelines, the Burra Charter, the Declaration of Oaxaca, the Florence Charter, the Washington Charter, the Nara Document, the Charter of Brasilia, this Declaration of San Antonio, etc. Several of these are discussed in the following sections.

\subsection{Nara Document on Authenticity}

In 1994, authenticity was the topic at the Nara (Japan) conference organized by the Japanese government Cultural Organization Restoration of Cultural Sites (ICOMOS). addresses authenticity in our contemporary world".
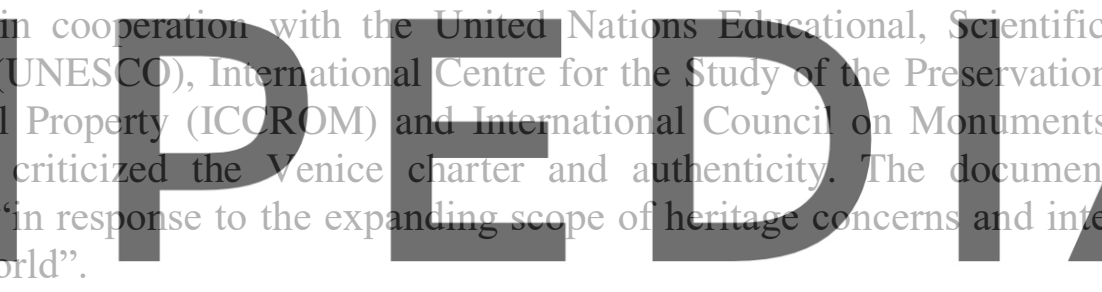

Article 11 states "All judgements about values attributed to cultural properties as well as

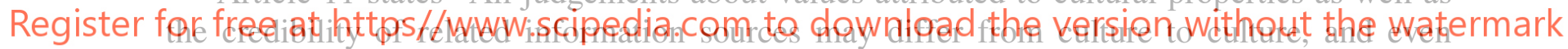

within the same culture. It is thus not possible to base judgements of values and authenticity within fixed criteria. On the contrary, the respect due to all cultures requires that heritage properties must be considered and judged within the cultural contexts to which they belong."

It nearly removes authenticity from the requirements for cultural context. From this, countries were encouraged to develop their own criteria for dealing with preservation and authenticity.

\subsection{Declaration of San Antonio}

In March 1996, the InterAmerican Symposium on Authenticity in the Conservation and Management of the Cultural Heritage was held in San Antonio, Texas, USA by the ICOMOS National Committees of the Americas to address the meaning of authenticity in preservation in the Americas. The Nara document was reviewed and critiqued. Recommendations were made to modify it by issuing a declaration [7].

When discussing authenticity and materials, it was stated that "..there are important sectors of our patrimony that are built of perishable materials that require periodic replacement in accordance with traditional crafts to ensure continued use. Similarly, there are 
heritage sites built of durable materials but that are subject to damage caused by periodic natural catastrophes, such as earthquakes, floods and hurricanes. In these cases, we also assert the validity of using traditional techniques for their repair, especially when those techniques are still in use in the region, or when more sophisticated approaches would be economically prohibitive." Thus there was an affirmation of protecting cultural heritage without limiting to authentic restorations.

\section{RESTORATION IN THE UNITED STATES}

The United States has numerous agencies that oversee historic preservation. At the national level, the National Park Service of the U.S. Department of the Interior controls historic preservation of national sites through the National Trust for Historic Preservation. Generally, each state has its own agency for state historical sites and finally local governments can have a regional agency. Often, determining the appropriate agency and designation is a challenge for any consultant. Several agencies are discussed as follows. Each has taken a local pragmatic approach to preservation.

\subsection{New York City}

The Landmarks Preservation Commission is a charter-mandated New York City commission. It is the largest municipal preservation agency in the United States. Created in 1965, it was formed to combat losses of historically significant buildings in New York City According to the Landmarks that represent New York City is to:

- Stabilize and improve property values

- Foster civic prid
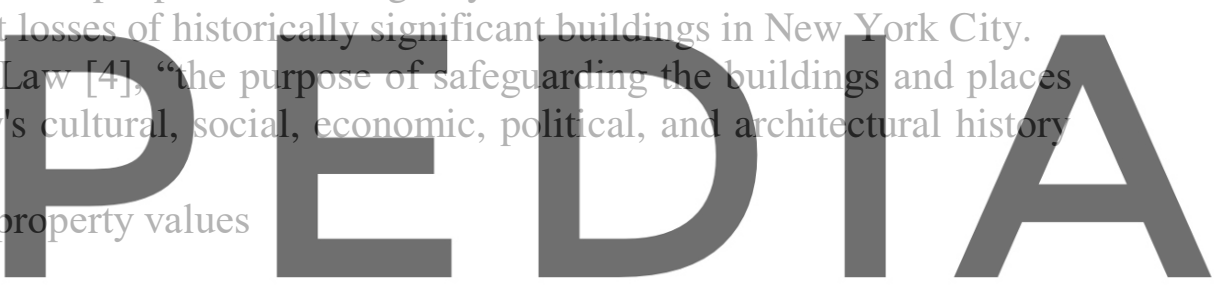

- Protect and enhance the City's attractions to tourists

Register for freetatngttpos Howawnscipedila.com to download the version without the watermark

- Promote the use of historic districts, landmarks, interior landmarks, and scenic

landmarks for the education, pleasure and welfare of the people of the City."

The 1964 Venice Charter is not mentioned in the law creating the commission although advocates probably were aware of its existence. Yet, there is no mention of maintaining authenticity as the leading component of preservation. It emphasizes financial reasons as a major driving force.

The commission operates under a set of rules [5]. Section 2-11 includes Repair, Restoration, Replacement and Re-Creation of Building Façades and Related Exterior Elements. Authenticity is addressed in Subsection (b)(3) "In all cases, except where noted, the repair, restoration, replacement or re-creation must match the original or historic materials and features in terms of its physical and aesthetic characteristics, including design, detail, profile, dimension, material, texture, tooling, dressing, color and finish, as applicable." In Subsection (b)(2), it states "Where replacement of large quantities of materials and/or significant architectural features is proposed, the applicant must provide an assessment of the deteriorated conditions warranting such replacement(s). Repair will be given priority over replacement if feasible." So, priority is given to repair over replacement but the rules provide a path to replacement. 
Subsection $(d)(1)$ requires "Replacement materials and features should match the original or historic material or feature in terms of physical and aesthetic characteristics. For purposes of this subdivision, this means that replacement material should be "in-kind" in terms of using the actual original or historic material and installation techniques. In-kind replacement should be prioritized and fully considered prior to proposing substitute materials." While in-kind materials are a priority for replacement, substitute materials are allowed under another section.

\subsection{Chicago}

Chicago is another major US city with a history of protecting its historic structures. The Commission on Chicago Landmarks was created in 1968. The program [8] addresses exterior qualities of buildings that are "significant historical or architectural features".

Chicago took the approach of basing its guidelines on the U.S. Secretary of the Interior's Standards for Rehabilitation of Historic Buildings [9] and extending them. Among their objectives they list "To identify, preserve, protect, enhance, and encourage continued utilization and the rehabilitation of such areas, districts, places, buildings, structures, works of art, and other objects having a special historical, community, architectural, or aesthetic interest or value to the City of Chicago and its citizens".

Several specific aspects of the standards include:

"Distinctive features, finishes, and construction techniques or examples of craftsmanship that characterize a historic property shall be preserved.

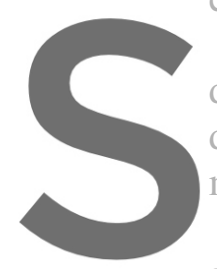

Deteriorated historic deterioration requires design, color, texture, missing features shall be Chemical or physical
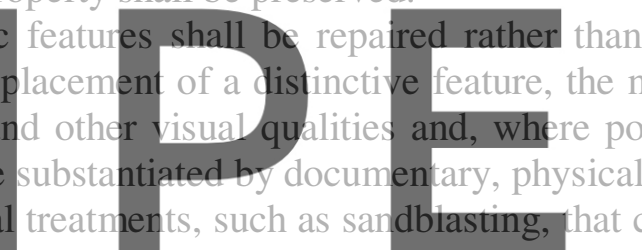
shall not be used. The su
gentlest means possible."

ace cleaning of structures, if appropriate, shall be undertaken using the replaced. Where the severity of
ew feature shall match the old in
sible, materials. Replacement of
or pictorial evidence.
ause damage to historic materials
ate, shall be undertaken using the

for replacement of deteriorated features, both cities chose to require the imitation of the original features and not distinguish them as was proposed in the Venice Charter. This is in keeping with both the Nara Document and the San Antonio Declaration which essentially suggest selfdetermination of authenticity.

\section{CASE STUDY- FAÇADE RESTORATION OF 1889 BROWNSTONE}

This project was completed in 1996. It occurred during a time period when the Nara Document and the San Antonio Declaration were redefining whether restorations needed to be authentic. It is not clear whether the redefinition by these organizations was ground breaking or actually a reflection of what communities and cultures were already doing.

Specifically, the city and state where this project occurred had been requiring authentic restoration; repairs were to be performed using original materials and original techniques. This project was the first known departure from authentic with an historic residential property.

Figure 1 shows its building in 1996 and in its current condition. The primary difference is attributed to the photography and daylight. The restoration was documented previously [10]. 

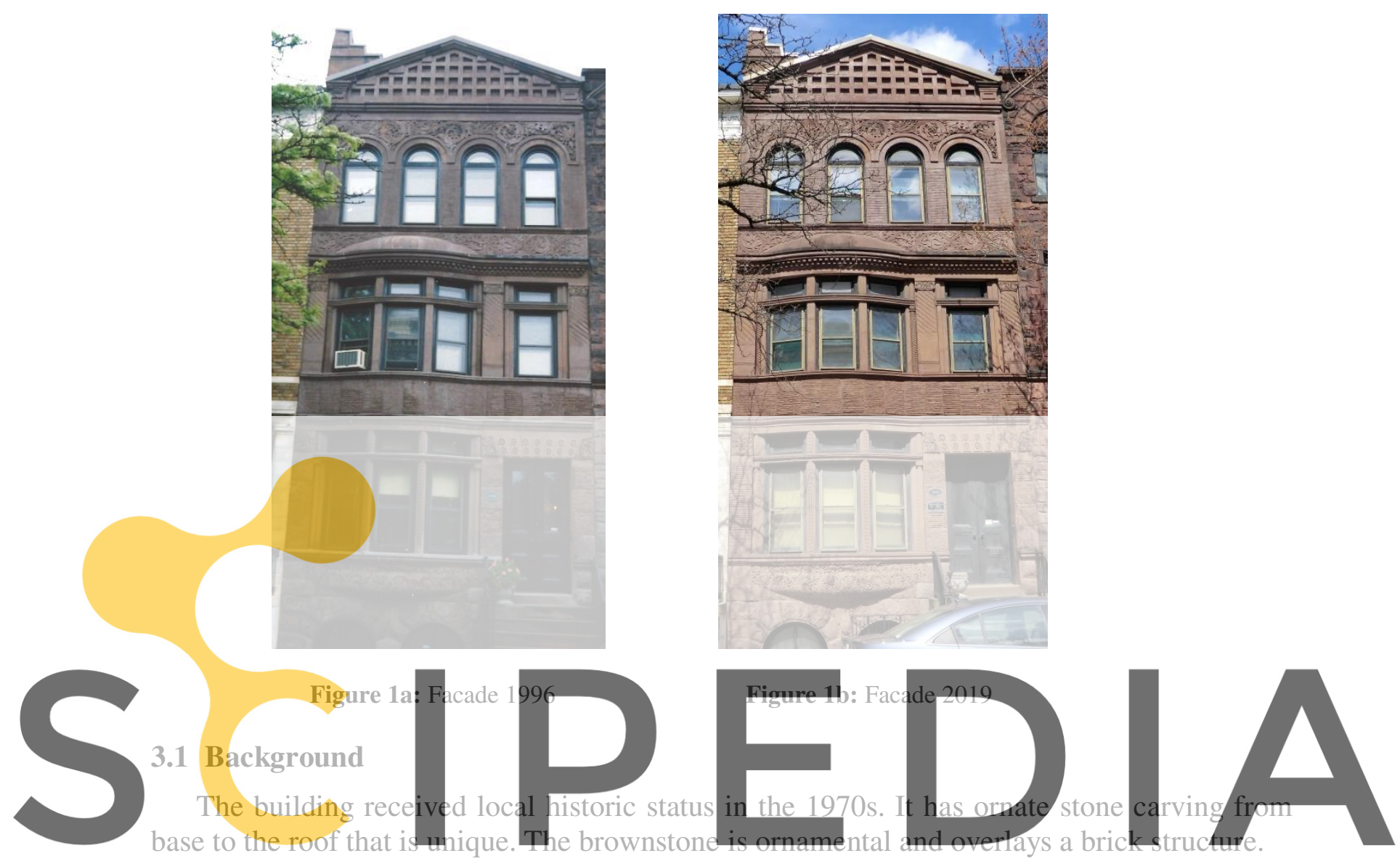

The Owner purchased the building c. 1973 but by 1991, pieces of the brownstone

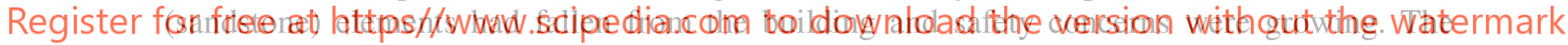

Owner started inquiries as to how to restore the façade. Aided by HAF, the local preservation organization, efforts were made to obtain grant funding but with no success. However in 1992, HAF was able to attract a number of preservation specialists to a Sandstone Colloquium which included a hands-on assessment of the building.

Following a day of façade examination by the specialists, over 50 attendees met to discuss the specialists' findings. To the dismay of the Owner, there were many ideas and the predominant recommendation was to add sidewalk protection in the short term. Long term they proposed that most of the brownstone be removed and replaced with new carved pieces. The projected repair cost was $\$ 250,000$ to $\$ 500,000$ which greatly exceeded the building value. This was beyond the means of the retired Owner on a pension.

The sidewalk scaffolding was quickly added and the Owner continued to seek funding. Finally in 1995, the deterioration accelerated and material losses were far worse; the Owner became desperate. City building officials were demanding action.

A mason restoration contractor who attended the initial symposium and who provided the sidewalk protection stepped in to offer assistance by meeting with HAF and the building officials. 
Historic buildings were expected to be restored using original materials and techniques. But the cost was beyond the Owner's ability to fund so negotiations with the city officials yielded an option:

Remove the brownstone and plaster coat the brick without any ornamentation.

The intent was to provide a safe façade even if it meant losing the aesthetic character of the facade. The contractor estimated this might cost $\$ 50,000$ to $\$ 60,000$. The Owner agreed to this level of funding for a budget.

Contrary to local practice, the contractor proposed an alternate solution with the budget of $\$ 60,000$. They would first remove the severely deteriorated brownstone and stabilize the areas still intact. Then they would re-evaluate the budget. The remaining funds would be dedicated to replacing the deteriorated brownstone with a brownstone patching material that could be carved to replicate the ornamentation. Patches would be anchored with stainless steel pins and wire. If funding was insufficient, plaster would be used as proposed by the city and some aesthetic features would be lost. This would met the city officials' goal to stabilize the façade yet restore some of the features. The city officials approved this concept and gave its first-ever building permit for a project which they did not know what the final appearance of the building would be.

\subsection{Restoration}

The Contractor recommended the Owner hire the author as her restoration engineer and the team was created.

The problems discover deterioration. Figure vertical pier, c) undersi material and patched cooperatively between the Engineer, Contract
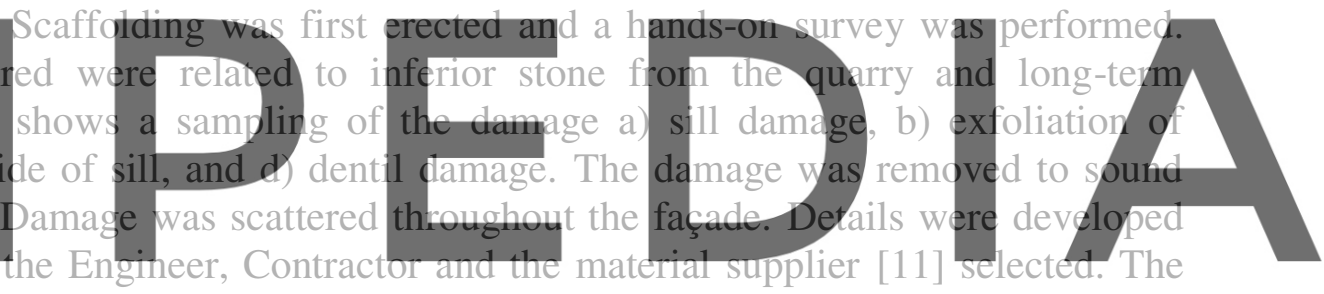

Owner anxiously watched the work proceed daily from across the street.

Register for free at https//www.scipedia.com to download the version without the watermark

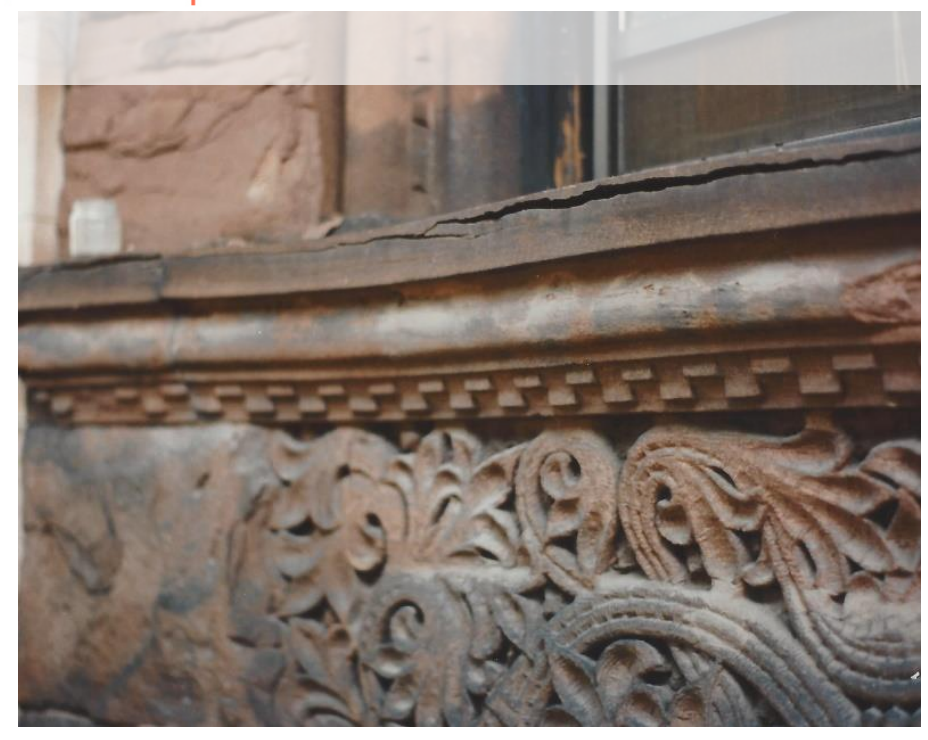

Figure 2: Representative problems from 1996 
The mason craftworker that installed and carved the patches was quite expert. He replicated the details exactly. In the end, the restoration contractor was able to repair all the deteriorated areas within the budget. The Owner, the HAF, and city officials were very pleased with the results. Their leap of faith in trusting the contractor was justified.

\subsection{Performance}

The façade condition in Figure 3 shows that the restoration has performed well for over 23 years. There is deterioration visible below a window sill (arrow, Figure 4). The brownstone is delaminating at the interface with the patches; it's likely the original deteriorated brownstone might not have been removed deep enough before installing the patch at this location. The current deterioration will need repairs in the coming years.

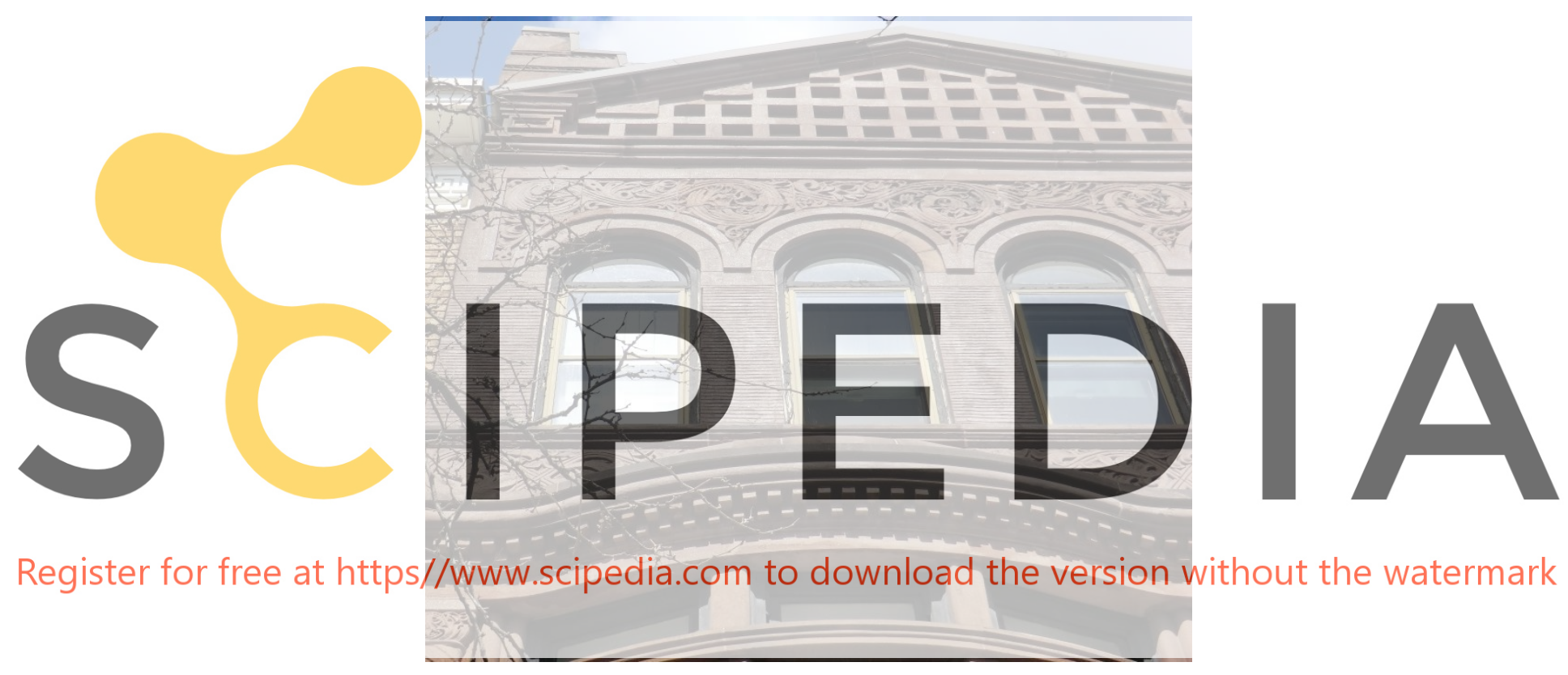

Figure 3: Façade 2019

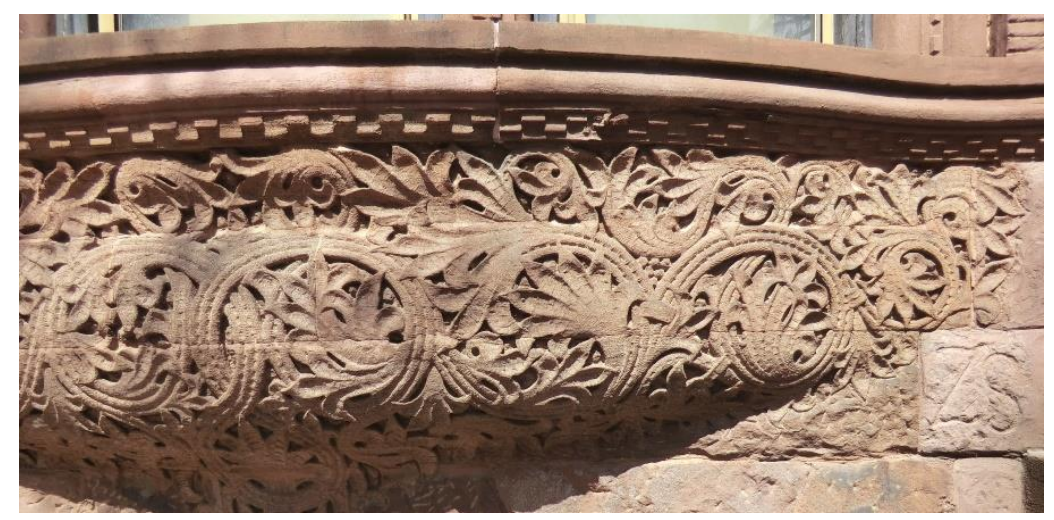

Figure 4: Sill deterioration 2019 
The ornamentation of the synthetically-patched façade is nearly undetectable under most climatic conditions. During rainy weather, the patches are evident since they do not absorb water the same as the brownstone (slightly visible in Figure 3). However since the façade faces the sun, it dries relatively quickly and the patches blend in again.

\section{SUMMARY/LESSONS LEARNED}

- While the case study demonstrates a successful synthetic restoration that has performed well for over two decades, the real point here is that the concept of maintaining authenticity was challenged for practical reasons. Authentic replacement was cost prohibitive and the Owner did not want to have a non-descript face for her building. Reality for the Owner was that she wanted to enjoy her building and that meant restoring the facade aesthetics even if they were not be authentic.

The restored facade maintains the value of the property and fits within the historic context of the neighborhood. Simply stabilizing the façade would have maintained public safety but would not have produced a culturally acceptable solution.

As a society, authenticity should be the highest priority for our restorations. But, not at the expense of losing the very fabric of the buildings and monuments that we enjoy. As previously noted, this project coincidentally occurred within the time period where authenticity was being challenged by the principles of the Nara Document and the San

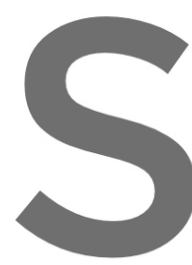
Antonio Declaration. Communtries (li
and owners were dediding what wa
materials and modern techniques to b
now seems to be a mainstay of most pr
Today, there are synthetic restoration
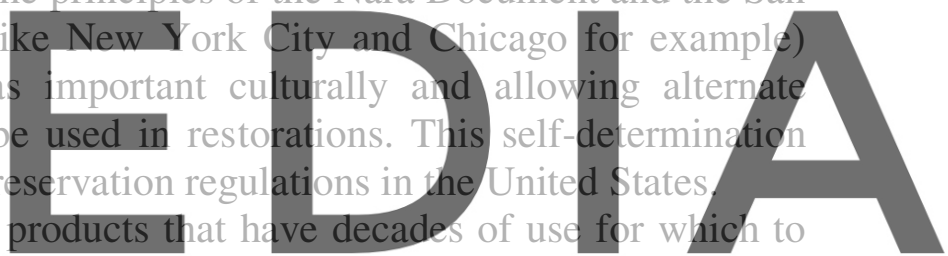

be judged. That was not the case in the 1990s.

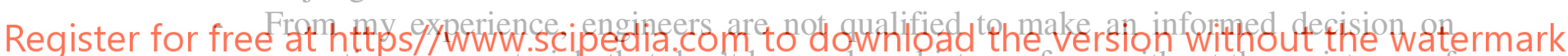
accepting new materials that don't have a long history of use without the assistance of specialists. This case study project had a chemist as the owner of the company supplying the patching material who provided the material expertise and an expert restoration contractor who could assess the material. They were integral to the judging the restoration design and making the best decisions given the limited budget.

- Judging the success of a restoration project can only be done through time. While heralded as a success in 1996, time has given us more data. Today, we know more about various synthetic products and proper installation techniques. The material used on this restoration has proven itself on numerous projects over the years and continues to be selected by restoration professionals.

Acknowledgements. Mr. Wil Ganem, Ganem Contracting Corp., and his team made the Owner's dream come true. Michael Edison, Edison Coatings Inc., provided the products and chemistry expertise for the patching system. 


\section{REFERENCES}

[1] The International Charter for the Conservation and Restoration of Monuments and Sites (Venice Charter), Association for Preservation Technology International Bulletin: The Journal of Preservation Technology, Vol. 37, No. 4, p. 51, (2006).

[2] Starn, R. Authenticity and historic preservation: towards an authentic history. History Of The Human Sciences Vol. 15 No. 1, SAGE Publications (London, Thousand Oaks, CA and New Delhi) pp. 1-16, [0952-6951(200202)15:1;1-16; 021070], 2002

[3] First International Congress of Architects and Technicians of Historic Monuments, Athens 1931.

[4] New York City Administrative Code, Title 25, Chapter 3, http://library.amlegal.com/nxt/gateway.dll/New\%20York/admin/title25landuse/chapter3landm arkspreservationpreservatio? $\mathrm{f}=$ templates $\$ \mathrm{fn}=$ default.htm $\$ 3.0 \$$ vid=amlegal:newyork_ny $\$ a n c=$ JD_T25C003

[5] Rules of New York City Landmarks Preservation commission, Title 63, Rules of City of New York, January 22, 2019,

https://www1.nyc.gov/assets/lpc/downloads/pdf/Rules/Rules\%20of\%20the\%20NYC\%20Lan dmarks\%20Preservation\%20Commission_01.22.2019.pdf

[6] Nara Conference on Authenticity in Relation to the World Heritage Convention, Nara, Japan, 1-6 November 1994, https://www.icomos.org/charters/nara-e.pdf

[7] InterAmerican Symposium on Authenticity in the Conservation and Management of the Cultural Heritage, San Antonio, TX, 27-30,March 1996,

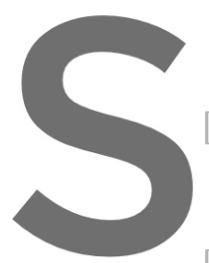
https://www.icomos.org/en/charters-and-texts/179-artic and-standards/188-th

[8] Guidelines For Alteration th https://www.chicago dards_for_Rehab_2015.pdf

[9] Secretary of the Interior's Standards for Rehabilitation of

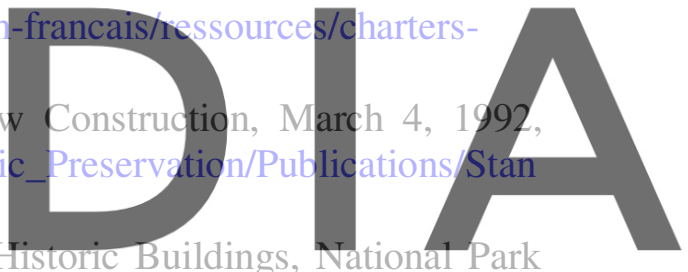
Service, Department of the Interior,

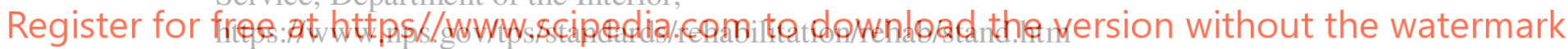

[10] Façade Restoration of an 1889 Brownstone, Proceedings of the 8th Canadian Masonry Symposium, Jasper, Alberta, pp.2226-275, 1998

[11] Custom SYSTEM 45 Masonry Patching \& Coating, Edison Coatings Inc., Plainville, CT. 